$22^{\text {nd }}$ International Conference on Harbor, Maritime and Multimodal Logistic Modeling \& Simulation

$17^{\text {th }}$ International Multidisciplinary Modeling \& Simulation Multiconference

\title{
Modelling of the Microrelief Impact to the Cross Country Movement
}

\author{
Jan Mazal ${ }^{*}$, Marian Rybanský ${ }^{1}$, Agostino G. Bruzzone ${ }^{2}$, Libor Kutěj ${ }^{1}$, Radomir \\ Scurek $^{3}$, Pavel Foltin ${ }^{1}$ and Daniel Zlatník ${ }^{4}$ \\ ${ }^{1}$ University of Defence, Brno, Czech Republic \\ ${ }^{2}$ Simulation Team, University of Genoa, Italy \\ ${ }^{3}$ VŠB-TU Ostrava, Czech Republic \\ ${ }^{4}$ Multinational Logistics Coordination Centre (MLCC), Prague, Czech Republic \\ *Corresponding author.Email address: jan.mazal@unob.cz
}

\begin{abstract}
Ground maneuver in natural environment is usually limited by a number of obstacles called micro relief, which are defined as man-made and natural both elevated and depressed topographic forms that cannot be expressed with regard to its relative small height differences. This terrain feature is present almost in all types of environment and extend the "off-road" path in average about certain coefficient, dependent on the type of the area. This extension should be taken in account in particular planning and decision making process tighten to a "just in time" concept, widely present for example in the operational environment. The aim of the article is to describe the methodology of evaluation of the influence of micro-relief shapes on the mobility of military vehicles. The article is based on the statistical determination of the extent of micro-relief shapes in the territory of the Czech Republic
\end{abstract}

Keywords: Micro Relief, Manoeuvre constrains, Approachability, Terrain Feature Modelling, Terrain Analysis, Cross-country Movement, Off-road Navigation

\section{Introduction}

Contemporary operational environment brings many aspects and challenges which were not apparent before, one of the relatively well known feature of the open terrain areas is the presence of microrelief shapes, imposing a certain limitation to the particular entity manoeuvre. Contemporary technology could deal with that problem by a 3D mapping of the area in $10 \mathrm{~cm}$ resolution or better, but this service is not always possible and manoeuvre planning has to rely on a standard maps or a rough 3D models, which could not accommodate so small features as a microrelief. Especially in a high level operational planning, the high ratio maps are used, excluding the microrelief feature, which could have a serious impact on an operational and logistic planning.

\section{State of the art analyses}

During the mentioned problem analyses and other related research evaluation, there were not found any publication dedicated to the mentioned problem. There exists a lot of papers oriented to the area of path/manoeuvre optimization, for instance J. Li, G. Deng et al. (Li et al., 2016) or papers talking about microrelief in context of water erosion Luo et al. (2018), or overall optimization of system capability distribution (Foltin et al., 2018) or other operational

(C) 2020 The Authors. This article is an open access article distributed under the terms and conditions of the Creative Commons Attribution (CC BY-NC-ND) license (https://creativecommons.org/licenses/by-nc-nd/4.0/). 
aspects of the path optimization (Kress, 2002; Rybar, 2002; Washburn \& Kress, 2009; Mokrá, 2012; Mazal et al., 2016; Rybansky, 2014; Rybansky \& Vale, 2009; Bruzzone, 2018; Bruzzone \& Massei, 2017; Nohel, 2019; Nohel et al., 2019; Nohel \& Flasar, 2020; Farlík et al., 2017), but no paper dealing with operational aspects of the microrelief was found. So the topic could not be considered as unfolded and from the operational perspective is still actual.

\section{Microrelief and its impact}

From the point of view of percent occurrence of particular types of microrelief forms at the territory of the Czech Republic prevail hollowed microrelief erosion rills, watersheds and man-made forms (first of all an embankments and earthworks alongside communications). The occurrence of microrelief forms on communications can be determined by use of the basic topographic maps 1:10,000 (depicted forms as a rule of height difference over $0.5 \mathrm{~m}$ ) or only approximately from topographic maps (digital model of terrain - DTM) 1: 25,000 (depicted forms of height difference over $2 \mathrm{~m}$ ). Parameters of microrelief forms of water-sheds (eventually of profiles of drainage systems) are with only minor exceptions unobtainable from the abovementioned topographic maps. Also the mathematic modelling of forms of erosion rills depending on physically geographic conditions at the particular section of geographic sphere would be very difficult.

The erosion is namely the result of many factors, firstly of:

- rain intensity;

- infiltration capacity of soil and soil mantle;

- chemical and physical features determining the erosion of rock and determining cohesiveness of the soil and mantle rock;

- vegetation directly affecting the stability and infiltration capacity of soil and makes the restraining factor of an erosion and water outflow;

- slope characteristics and direction characteristics of watercourses and their watersheds as well as other factors.

We differ:

- depth erosion when the stream deepens the stream-bed;

- lateral erosion when the stream broadens the stream-bed.

The formation of contra-flow winding bends of watercourse - meanders is related to lateral ero-sion. The meander strip is frequently broader than the stream-bed of primary watercourse and makes the significant restriction for the cross-country movement evaluation in the event that the meanders pass over the direction of vehicle movement crosswise as well as a valleys undulate lengthwise. The essential pa-rameters to the assessment of microrelief forms impact on cross-country movement are as follows:

- slope gradient of microrelief form;

- height of terrain step;

- width of microrelief form, e.g. of scarp, trench, watercourse.

Figure 1: Parameters of evaluation of the essential microrelief forms

\begin{tabular}{|c|c|c|c|}
\hline Number & Name & Form design & Evaluating param eters \\
\hline 1 & embankment & & 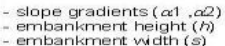 \\
\hline 2 & excavation & & $\begin{array}{l}\text { - slope gradients }(\alpha 1, \alpha, \alpha) \\
\text { - excavation depth }(h) \\
\text { - excavation width (s) } \\
\text { excavan }\end{array}$ \\
\hline 3 & delve, crater & & $\begin{array}{l}\text { - slope gradients }(\alpha 1, \infty 2) \\
\text { deve depth (m1) } \\
\text { - delve width }(s)\end{array}$ \\
\hline 4 & $\begin{array}{l}\text { terrain step } \\
\text { (climbing) }\end{array}$ & & - step height $(h)$ \\
\hline 5 & $\begin{array}{l}\text { terrain step } \\
\text { (descent) }\end{array}$ & & - step height $(h)$ \\
\hline 6 & $\begin{array}{l}\text { trench, scarp } \\
\text { (passing) }\end{array}$ & & - trench width $(s)$ \\
\hline
\end{tabular}

If a vehicle cannot overcome a microrelief form, it has to by-pass it and the vehicle route then lengthens. Even if such an event does not mean a vehicle deceleration on each occasion, the resulting impact on overall time of movement will be similar to the situation that a vehicle drives on direct route but with decreased speed by impact of relief gradient or of the other geographic factor. On the vehicle respective movement (lengthened) caused by obstruction by-passing, the following parameters of impassable microrelief forms have the impact:

- number of microrelief forms;

- length of microrelief forms;

- orientation of microrelief forms with regard to vehicle path axis;

- overall structure (space distribution of microrelief forms).

\section{Approach to the Solution}

The determination of the extension of the vehicle route due to microrelief limitations was calculated by statistical evaluation of the shortest route found from randomly selected points (with the distance of $10 \mathrm{~km}$ ) on a synthetic and real model of microrelief displacement. The computational algorithm of the route works on the principle of iterative search of minimal anti-collision junctions on the destination line (from the current point) approximated by $2 \mathrm{D}$ 
vectors. An algorithm works with input data model, based on statistical evaluation of 1/25 000 maps, generates a simplified, but suitable terrain model with randomly distributed microrelief shapes. However, this database can be read from any other source, if needed. The basic work area was chosen as a square with the edge of $10 \mathrm{~km}$.

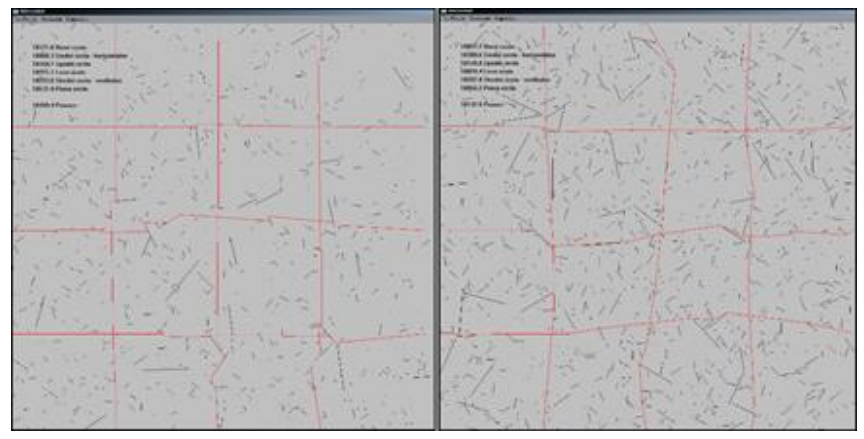

Figure 2: Result of the simulation, an average extension of $10 \mathrm{Km}$ direct path, left - non-optimized: $10399.4 \mathrm{~m}$ and right - optimized: 10132.5m

This procedure seems relatively effective and the gives the result of average path extension about 5 to 8 percent for a flat terrain (statistical date set was composed of 36,000 measurements on all types of terrain). This algorithm takes into account that as soon as an obstacle is encountered, it proceeds along to one of its vertices with shortest onward path to the target point and continue this process until the destination point is reached. However, this is very simple approach and there is the chance to implement additional optimization, the initial version of the path finding gives promising results. To speed up the search for the first/closest microrelief collision, the spatial (2D) indexing of microreliefs (vectors) was used and hierarchy of calculations, like collision check:

$$
\begin{aligned}
c_{1}= & \left(y_{i 1}-y_{i 2}\right) x_{j 1}+\left(x_{i 2}-x_{i 1}\right) y_{j 1}-\left(y_{i 1}-y_{i 2}\right) x_{i 1}-\left(x_{i 2}-x_{i 1}\right) y_{i 1} \\
c_{2}= & \left(y_{i 1}-y_{i 2}\right) x_{j 2}+\left(x_{i 2}-x_{i 1}\right) y_{j 2}-\left(y_{i 1}-y_{i 2}\right) x_{j 1}-\left(x_{i 2}-x_{i 1}\right) y_{j 1} \\
c_{3}= & \left(y_{j 1}-y_{j 2}\right) x_{i 1}+\left(x_{j 2}-x_{j 1}\right) y_{i 1}-\left(y_{j 1}-y_{j 2}\right) x_{j 1}-\left(x_{j 2}-x_{j 1}\right) y_{j 1} \\
c_{4}= & \left(y_{j 1}-y_{j 2}\right) x_{i 2}+\left(x_{j 2}-x_{j 1}\right) y_{i 2}-\left(y_{j 1}-y_{j 2}\right) x_{j 1}-\left(x_{j 2}-x_{j 1}\right) y_{j 1} \\
& \text { Where: } \\
& c_{1-1} c_{4}-\text { vector multiplication coefficients } \\
& x_{i}, y_{i} \text { - components of I vector } \\
& x_{j i}, y_{i} \text { - components of } J \text { vector }
\end{aligned}
$$

Collision of $\mathrm{I}$ and $\mathrm{J}$ vectors is present just if coefficients $\mathrm{c} 1$ and $\mathrm{c} 2$ and also c3 and c4 differs in sign, if not, no other calculations are needed and program continue with another iteration/step.

In the case of additional optimization, the search was upgraded about a shortcut avoiding the intersection point between the microrelief and direct line to the target point, so, a path proceeds only along the vertices of individual microrelief shapes. The upgraded algorithm takes the non-optimized path and check if the path intersects at least one microrelief (otherwise it ends - the path is optimal and at the shortest as possible). If so, then start recursive check for direct connection of the microrelief vertices from the original path.

As a final step, calculate the path length:

$$
D_{c}=\sum_{n=1}^{S-1} \sqrt{\left(x_{n+1}-x_{n}\right)^{2}+\left(y_{n+1}-y_{n}\right)^{2}}
$$

Dc - path length,

$S$ - the number of vertices in the path,

$\mathrm{x}, \mathrm{y}-\mathrm{x}, \mathrm{y}$ axes of the particular vertex,

$n$ - index within the set of vertices.

The optimization principle is demonstrated on the following figure (dash line):

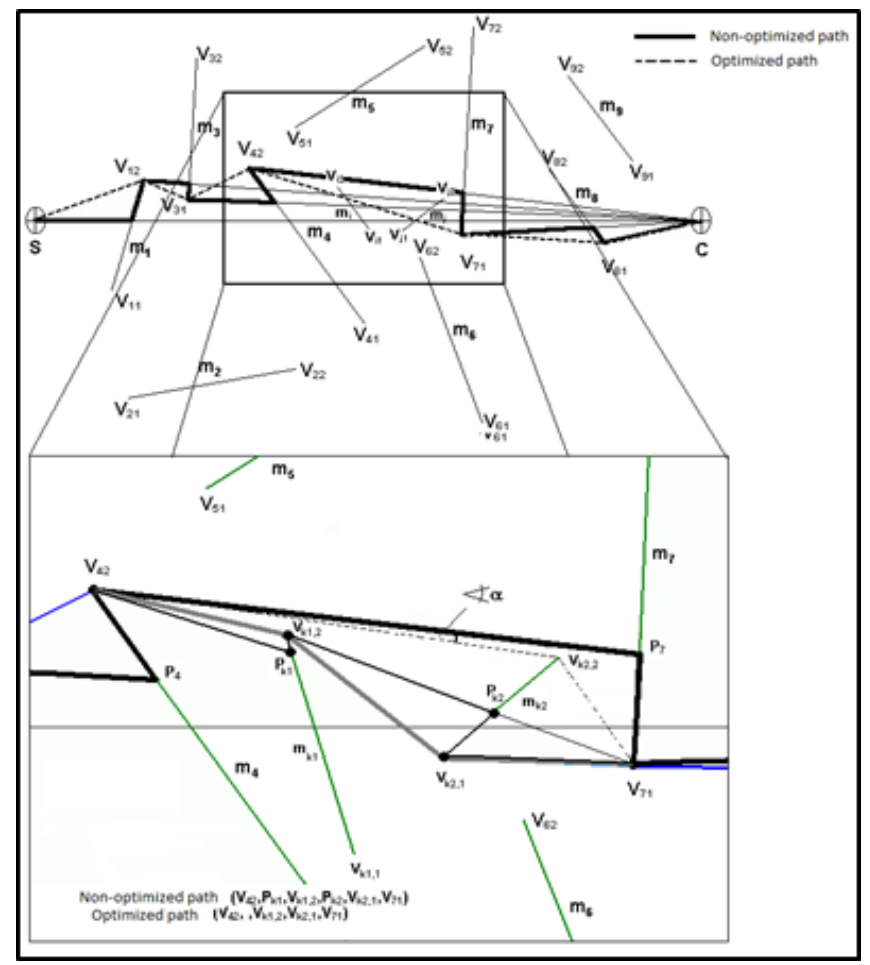

Figure 3. Demonstration of the collision of some microrelief shapes with the optimal connection of points $\mathrm{V}_{42}$ and $\mathrm{V}_{71}$, during the process of path optimization

This optimization process on average shortens the initial path (depending on the number and type of microrelief shapes) up to a 1 percent elongation of the possible shortest (direct line) path. With comparison of 5 to 8 percent elongation of the initial non-optimized path search (in any case the given extension depends on the type of relief, there were mentioned the best achievable average cases) it is significant performance upgrade.

In addition, mentioned optimization process is relatively efficient (fast) and can shorten the extension of the non-optimized path in some cases up to 25 times, as illustrated on the following graphs, however, this algorithm may not always find the absolutely shortest path. 


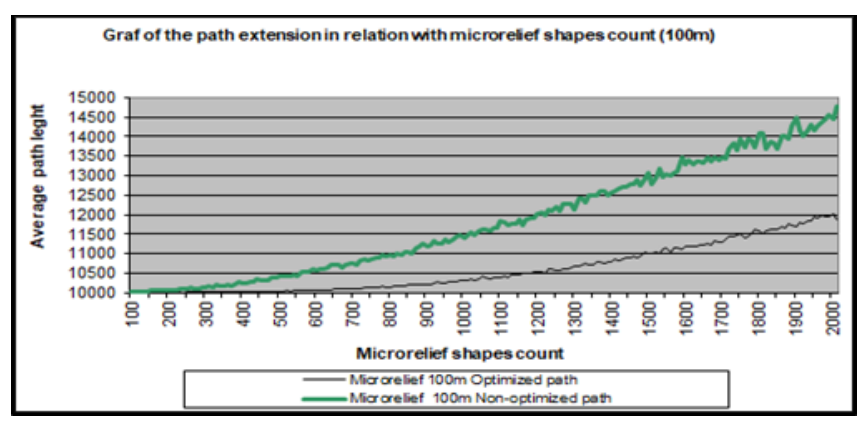

Figure 4: Graphs of the path extension relation to the microrelief count (microrelief 100m)

As it is visible on following graphs, the length with microrelief count has an serious impact on the average maneuver, particularly when density of the microrelief longer than $100 \mathrm{~m}$ reaches the density more than 8 microreliefs per square kilometer

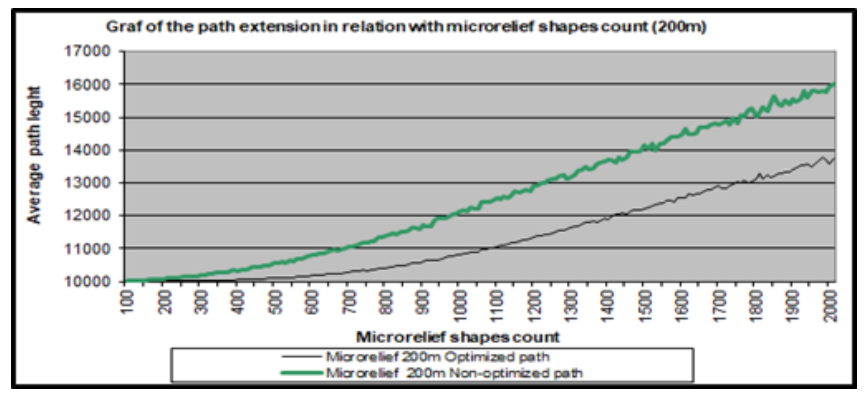

Figure 5: Graphs of the path extension relation to the microrelief count (microrelief 200m)

Also it apparent, that, the extension trend is parabolic until this limit and continues almost linearly after. The following research will be focused on expansion of simulations count and search for the generic expression of this relation if it exists.

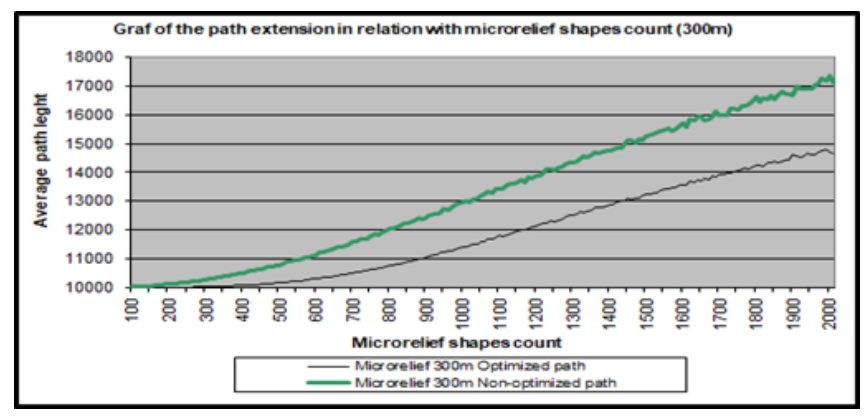

Figure 6: Graphs of the path extension relation to the microrelief count (microrelief 300m)

There is necessary to mention, that contemporary statistical survey is based on more than 1,5 mil generated microrelief models and over 52 mil. different possible paths were calculated within almost 50 hours of simulation.

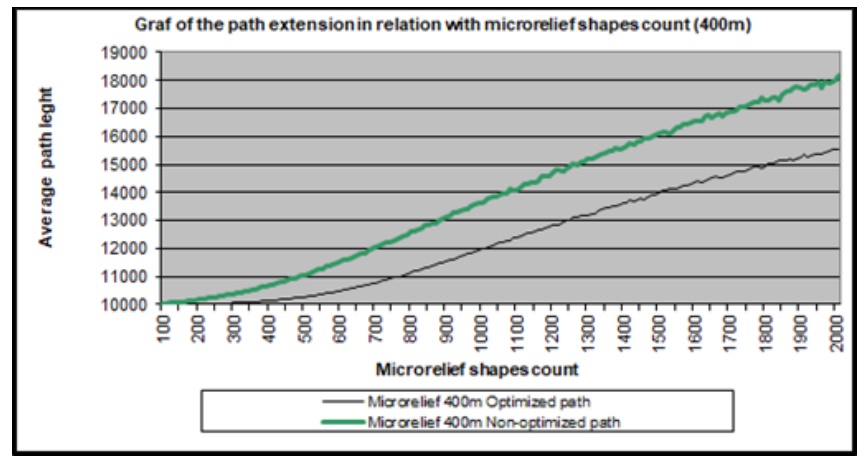

Figure 7: Graphs of the path extension relation to the microrelief count (microrelief 400m)

\section{Conclusions}

The importance of effective operational planning aspects in various areas (as a decision support component) is constantly on increase. There appears a great potential in aggregation of operational relations and findings integrated in the human high-level reasoning. These features could be extracted by a Model-ling and Simulation methods and play important aspect in an operational planning.

Presented solution shows the possible approach in the area of operational manoeuvre extension, related to the permanent characteristics of the terrain and describe the methodology of evaluation of the influence of micro-relief shapes on the mobility of military vehicles. The article was based on the statistical determination of the extent of micro-relief shapes in the territory of the Czech Republic. These shapes were detected in various geomorphological relief types using topographic maps of 1:10 000 and the Digital Ele-vation Model (DEM 5) with the density of $1 \mathrm{x} 1 \mathrm{~m}$. The article describes both the methodology of calcula-tions of possible collisions of the tactical entity with the terrain, as well as the calculation of the optimal route avoiding micro-relief obstacles.

Further research will look for the correlation between synthetic model and real terrain in terms of vali-dation of some previous assumptions about terrain categories and also look for the "generic" model for operational purposes to upgrade the estimated total sum of the particular paths for logistic planning and preparation.

\section{References}

Bruzzone, A.G. \& Massei, M. (2017). "Simulation-Based Military Training", in Guide to Simulation-Based Disci-plines, Springer, pp. 315-361

Bruzzone, A.G. (2018). "MS2G as Pillar for Developing Strategic Engineering as a New Discipline for Complex Problem Solving", Keynote Speech at I3M, Budapest, September

Farlík, Jan, Starý, Vadim, Časar, Josef. Simplification of Missile Effective Coverage Zone in Air Defence 
Simulations. In: Proceedings of the 2017 International Conference on Military Technologies (ICMT). Piscataway, NJ 08854-4141 USA: Institute of Electrical and Electronics Engineers Inc., 2017, p. 733-737. ISBN 978-1-5386-1988-9.

FOLTIN, Pavel, VLKOVSKÝ, Martin, MAZAL, Jan, HUSÁK, Jan, BRUNCLÍK, Martin. Discrete Event Simulation in Future Military Logistics Applications and Aspects. In: Modelling and Simulation for Autonomous Systems. Ro-ma: Springer International Publishing AG, 2018, p. 410-421. ISSN 0302-9743. ISBN 978-3-319-76072-8.

J. Li, G. Deng, C. Luo, Q. Lin, Q. Yan and Z. Ming, "A Hybrid Path Planning Method in Unmanned Air/Ground Vehicle (UAV/UGV) Cooperative Systems," in IEEE Transactions on Vehicular Technology, vol. 65, no. 12, pp. 9585-9596, Dec. 2016, doi: 10.1109/TVT.2016.2623666.

Jan Nohel, Petr Stodola and Zdeněk Flasar (April 3rd 2019). Model of the Optimal Maneuver Route, Path Planning for Autonomous Vehicles - Ensuring Reliable Driverless Navigation and Control Maneuver, Umar Zakir Abdul Hamid, Volkan Sezer, Bin Li, Yanjun Huang and Muhammad Aizzat Zakaria, IntechOpen, DOI: 10.5772/intechopen.85566. Available from: https://www.intechopen.com/books/pathplanning-for-autonomous-vehicles-ensuringreliable-driverless-navigation-and-controlmaneuver/model-of-the-optimal-maneuverroute.

Luo, J., Zheng, Z., Li, T. et al. Changes in micro-relief during different water erosive stages of purple soil under simulated rainfall. Sci Rep 8, 3483 (2018). https://doi.org/10.1038/s41598-018-21852-6

M. Kress (2002). Operational Logistics: The Art and Science of Sustaining Military Operations. Springer.

Mazal, J., Stodola, P., Procházka, D., Kutěj, L., Ščurek, R., Procházka, J. (2016). Modelling of the UAV safety ma-noeuvre for the air insertion operations. In: Modelling and Simulation for Autonomous Systems, MESAS 2016. Rome: Springer International Publishing, p. 337-346. ISSN 03029743. ISBN 978-3-319-47604-9.

Mokrá, I. (2012) Modelový přístup k rozhodovacím aktivitám velitelů jednotek $\mathrm{v}$ bojvých operacích. Disertační práce. Brno: Univerzita obrany v Brně, Fakulta ekonomiky a managementu. $120 \mathrm{~s}$.

Nohel, Jan, Flasar, Zdeněk. Maneuver control system CZ. In: Mazal J., Fagiolini A., Vasik P. Modeling and Simulation for Autonomous Systems. MESAS 2019. Lecture Notes in Computer Science, vol 11995. Switzerland, Cham: Springer, 2020, p. 379-388. ISBN 978-3-030-43889-0. DOI: $10.1007 / 978-3-$ 030-43890-6_31.

Nohel, Jan. Possibilities of Raster Mathematical
Algorithmic Models Utilization as an Information Support of Mi-litary Decision Making Process. In: Modelling and Simulation for Autonomous Systems. Cham, Switzerland: Sprin-ger: NATO Modelling and Simulation Centre, 2019, p. 553-565. ISSN 03029743. ISBN 978-3-030-14984-0. DOI: 10.1007/978-3-030-14984-0_41.

Rybanský, M. \& Vala, M. (2009). Relief Impact on Transport. In.: ICMT'09 - International conference on military technologies 2009, Brno (Czech Republic), 9 pp, ISBN 978-80-7231-649-6 (97880-7231-648-9 CD).

Rybansky, M. (2014). Modelling of the optimal vehicle route in terrain in emergency situations using GIS data. In: 8th International Symposium of the Digital Earth (ISDE8) 2013, Kuching, Sarawak, Malaysia 2014 IOP Conf. Se-ries.: Earth Environmental Science 18 012071, doi:10.1088/17551315/18/1/012131, http://dx.doi:10.1088/17551315/18/1/012131. ISSN 1755-1307.

Rybar, M. (2000) Modelovanie a simulacia vo vojenstve. Ministerstvo obrany Slovenskej republiky, Bratislava.

Washburn, A. \& Kress, M. (2009) Combat Modeling. International Series in Operations Research \& Management Science. Springer. 